\title{
Genetic and environmental control of the Verticillium syndrome in Arabidopsis thaliana
}

\author{
Eva Häffner ${ }^{1}$, Petr Karlovsky², Elke Diederichsen ${ }^{1^{*}}$
}

\begin{abstract}
Background: Verticillium spp. are major pathogens of dicotyledonous plants such as cotton, tomato, olive or oilseed rape. Verticillium symptoms are often ambiguous and influenced by development and environment. The aim of the present study was to define disease and resistance traits of the complex Verticillium longisporum syndrome in Arabidopsis thaliana (L.) Heynh. A genetic approach was used to determine genetic, developmental and environmental factors controlling specific disease and resistance traits and to study their interrelations.

Results: A segregating F2/F3 population originating from ecotypes 'Burren' (Bur) and 'Landsberg erecta' (Ler) was established. Plants were root-dip inoculated and tested under greenhouse conditions. The Verticillium syndrome was dissected into components like systemic spread, stunting, development time and axillary branching. Systemic spread of $V$. longisporum via colonisation of the shoot was extensive in Ler; Bur showed a high degree of resistance against systemic spread. Fungal colonisation of the shoot apex was determined by (a) determining the percentage of plants from which the fungus could be re-isolated and (b) measuring fungal DNA content with quantitative realtime PCR (qPCR). Four quantitative trait loci (QTL) controlling systemic spread were identified for the percentage of plants showing fungal outgrowth, two of these QTL were confirmed with $\mathrm{QPCR}$ data. The degree of colonisation by V. longisporum was negatively correlated with development time. QTL controlling development time showed some overlap with QTL for resistance to systemic spread. Stunting depended on host genotype, development time and seasonal effects. Five QTL controlling this trait were identified which did not co-localize with QTL controlling systemic spread. V. longisporum induced increased axillary branching in Bur; two QTL controlling this reaction were found.

Conclusions: Systemic spread of $V$. longisporum in the host as well as resistance to this major disease trait are described for the first time in natural $A$. thaliana accessions. This creates the possibility to study a major resistance mechanism against vascular pathogens in this model plant and to clone relevant genes of the involved pathways. Stunting resistance and resistance to systemic spread were controlled by different QTL and should be treated as separate traits. Developmental and environmental effects on pathogenesis and resistance need to be considered when designing and interpreting experiments in research and breeding.
\end{abstract}

\section{Background}

Verticillium spp. are vascular fungal pathogens that induce diverse disease symptoms and severe yield losses on a broad range of dicotyledonous plants [1]. Disease symptoms include wilting, chlorosis, stunting, vascular discoloration, defoliation or premature seed ripening. Infected plants often show unspecific reactions similar

\footnotetext{
* Correspondence: elked@zedat.fu-berlin.de

'Freie Universität Berlin, Institut für Biologie - Angewandte Genetik, AlbrechtThaer-Weg 6, 14195 Berlin, Germany

Full list of author information is available at the end of the article
}

to those which occur during senescence or under environmental stress conditions.

In susceptible crops the infection starts in the root and proceeds into the shoot by systemic spread via the transpiration stream in the xylem $[2,3]$. Certain conditions, for example developmental events, can influence the initiation of the systemic phase [3]. Resistance to systemic spread has been shown to be a major component of Verticillium resistance for many hosts [3-9]. Resistance to systemic spread is regarded as a type of resistance that reduces the rate of epidemic development in the field [10]. Rate-reducing resistance has been

Ciomed Central

(c) 2010 Häffner et al; licensee BioMed Central Ltd. This is an Open Access article distributed under the terms of the Creative Commons Attribution License (http://creativecommons.org/licenses/by/2.0), which permits unrestricted use, distribution, and reproduction in any medium, provided the original work is properly cited. 
shown to be a major component of field resistance in economically important crops. In soybean for example, yield depends strongly on rate-reducing resistance against Phytophthora root and stem rot [11] and sudden death syndrome caused by Fusarium [12]. In both cases a major component of rate-reducing resistance is the host's ability to restrict fungal colonisation of the plant tissue $[12,13]$

$V$. longisporum (Stark) Karapapa is a soil-borne fungal pathogen specialised for cruciferous hosts [14]. During the last decades, it has become a serious threat to oilseed rape in Central and Northern Europe [15,16]. Since there are no efficient fungicides available against this pathogen, resistance breeding is the most promising approach to control the disease. To date, only quantitative resistance against $V$. longisporum is known [17]. Quantitative resistance is characterised by being incomplete and conditioned by multiple genes of partial effect [18]. Often, quantitative resistance to pathogens is a pleiotropic effect of genes affecting growth and development $[18,19]$. The situation in the $V$. longisporum-Brassicaceae-pathosystem is further complicated by the diversity of the symptoms induced. Chlorosis and stunting are among the most obvious symptoms in root-dip inoculated Brassica plants and are often used to assess disease progression in greenhouse experiments [4,20,21]. Mapping of resistance QTL has mostly been performed on the basis of these symptoms [22]. However, stunting has never been observed in the field. The prevalent symptom on oilseed rape in the field is premature ripening [23], which is accompanied by systemic spread, extensive formation of microsclerotia on shoot tissue, and yield loss [24]. Systemic spread in the host plant has been shown to be a specific component of the $V$. longisporum-Brassica-interaction. Whereas $V$. dahliae-infection is mainly restricted to the roots, $V$. longisporum is capable of invading the shoot system of susceptible Brassica genotypes [2,3]. The transition to flowering has been shown to be a crucial developmental stage promoting systemic spread [3], but in extremely susceptible genotypes systemic spread has been observed in even earlier stages [24]. Symptom severity corresponded with the presence of $V$. longisporum in the shoot system for Brassica spp. in greenhouse experiments [4,5]. Systemic spread is regarded as a main indicator for disease severity in the field [24]. The genetic basis of resistance to systemic spread in Brassica remains unknown.

Recent studies used $A$. thaliana as a model organism to further elucidate the genetic basis of Verticillium resistance and disease traits [25-29]. $V$. dahliae and $V$. longisporum are capable of inducing symptoms in $A$. thaliana comparable to those in Brassica. Differences in symptom severity have been observed among natural accessions of $A$. thaliana or in specified mutants. A locus on chromosome 4 , Vet1, was shown to confer resistance to chlorosis and it also delayed flowering after Verticillium infection [29]. Two QTL were mapped to different chromosomal positions that were associated with resistance to chlorosis, and a new allele of $r f o 1$ (resistance to Fusarium oxysporum) was described that increased the resistance to fresh weight loss caused by $V$. longisporum [26]. By testing defined A. thaliana mutants for their reaction towards Verticillium infection, it has been shown that processes as diverse as ethylene signalling [26,27,29], R-gene signalling [26] and post-transcriptional gene-silencing [25] are involved in resistance against Verticillium. Disease severity was recorded as stunting, fresh weight loss and chlorosis. In two of these studies the degree of colonisation by $V$. longisporum in the host was recorded. The higher susceptibility of ecotype 'Col-0' to Verticillium-induced chlorosis was not accompanied by higher numbers of colony-forming units in whole plants when compared to ecotype 'C24' [29]. Mutants with impaired endogenous gene silencing showed increased Verticillium susceptibility in terms of stunting and chlorosis and also more fungal biomass compared to wild type [25]. Relatively few research studies focus on the natural genetic resources for $V$. longisporum-resistance. Brassica as well as $A$. thaliana accessions may still harbour numerous unknown genes capable of influencing the interaction with $V$. longisporum $[17,20,26]$.

The aim of the present study was to localise genomic regions in $A$. thaliana that influence disease and resistance traits in order to identify the associated genes and pathways using a QTL mapping approach. An F2/F3 mapping population was derived from a cross between two ecotypes that displayed striking differences in their interaction with $V$. longisporum. Special emphasis was placed on the definition of disease and resistance traits such as systemic spread and stunting. The degree of systemic fungal spread into the apical parts of the shoot, a trait whose natural variation has not been examined in a genetic study of $A$. thaliana before, was determined with two different methods: Re-isolation from apical shoot segments and qPCR of fungal DNA. To analyse the developmental implications of the disease the branching pattern and the duration of the development were recorded. To study disease traits in closer similarity to the natural situation, a greenhouse testing procedure was used. The dissection of the complex syndrome in a genetic study allowed the detection of QTL controlling different traits, to investigate their relationships and to draw conclusions regarding their role for disease and resistance.

\section{Methods}

\section{Material}

A. thaliana ecotypes Bur-0 and Ler-0 were originally obtained from the Arabidopsis Information Service (AIS) Frankfurt [30] and maintained in house. The 
V. longisporum isolate '43' [31] was used for infestation experiments.

\section{Fungal culture and preparation of spore suspension}

Fungal stocks with $1-3 \times 10^{6}$ conidia/ml were stored in glycerol:water $(1: 4)$ at $-75^{\circ} \mathrm{C}$. Conidial suspensions for inoculation were produced in liquid Czapek-Dox medium on a shaker at $20^{\circ} \mathrm{C}$ for 8 days and filtered through sterile gauze. Spore densities were determined using a haemocytometer (Neubauer improved). For inoculation, spore suspensions were diluted to $1 \times 10^{6}$ conidia $/ \mathrm{ml}$ with sterile tap water.

\section{Infestation experiments}

For all greenhouse infestation experiments, a root-dip inoculation procedure [31] was applied which was modified for $A$. thaliana as follows. Seeds were stratified at $8^{\circ} \mathrm{C}$ for 2 days before sowing and plantlets were grown in a mix of commercial potting soil (Einheitserde Typ P) and sand (3:1 vol. parts) under long-day conditions (16 $\mathrm{h}$ light) at $20^{\circ} \mathrm{C}$ for 19 days. Supplementary lighting was provided using sodium vapour lamps. After uprooting and cutting the root tips plantlets were dipped in a conidial suspension for $1 \mathrm{~h}$. Controls were mock-inoculated in diluted Czapek-Dox medium without spores. Thirty plants were planted per $20 \times 30 \mathrm{~cm}$ plastic tray filled with $1.5 \mathrm{l} \mathrm{soil} / \mathrm{sand}$ mix. Inoculated plants were grown in long-day in the greenhouse at $18-28^{\circ} \mathrm{C}$ until maturity of the first siliques. Then the height of the aerial parts of the plant (from the hypocotyl to the tip of the longest stalk), their fresh weight, the branching pattern and colonisation of the apical part of the shoot were determined. To test whether infection requires root injury, individual plantlets were raised in pots of 5 $\mathrm{cm}$ diameter for 19 days as described above, and then 5 $\mathrm{ml}$ of conidial suspension were pipetted into the soil next to the hypocotyls of the seedling. Three F3 infestation experiments were carried out. Experiment 1 (E1) was started in January (winter experiment), experiment 2 (E2) in March and experiment 3 (E3) in April (referred to as spring experiments). Altogether, 108 families were tested. Each experiment comprised 60 F3-families which were partly overlapping between the experiments. The overlap was ten F3-families between E1 and E2, 31 between E2 and E3, and 32 between E1 and E3. Ten selected F3families, parents and $\mathrm{F} 1$ were analysed in every experiment. Of each F3-family, 30 inoculated and 15 mock-inoculated plants were tested. The parental ecotypes Ler and Bur were tested at least eleven times during all seasons of the year with at least 30 replicates per experiment.

\section{Determination of systemic fungal spread}

Systemic spread of $V$. longisporum was observed to occur during flowering (see Results) and was therefore determined at the onset of silique maturity. To determine systemic spread by re-isolation, segments of approx. $3 \mathrm{~cm}$ length were cut from the apex of the main shoot axis of each plant, surface-sterilised with $0.1 \%$ (w/ v) sodium hypochlorite solution and subsequently dipped in $70 \%(\mathrm{v} / \mathrm{v})$ ethanol. After rinsing three times in sterile water, the segments were transferred to Petri dishes containing $9 \mathrm{~g} / \mathrm{l}$ agar, $10 \mathrm{~g} / \mathrm{l}$ malt extract and 100 $\mathrm{mg} / \mathrm{l}$ streptomycin. $V$. longisporum outgrowth was recorded after 1 and 2 weeks. One shoot segment per plant was plated and the percentage of colonised shoot segments of the total number of shoot segments per F3family was calculated (degree of colonisation). In experiment E3, apical pieces of the main shoot of parents, F1 and F3-families were also analysed for the amount of fungal DNA in the plant tissue by quantitative real-time PCR. Standards of $V$. longisporum DNA were prepared as described [32]. Real-time PCR based on internal transcribed sequences of ribosomal RNA genes with SYBR Green fluorescence monitoring was used for the quantification of fungal DNA in plant tissue [2]. The primers were designed to amplify Verticillium spp. but not other organisms potentially infecting A. thaliana. Usually three samples consisting of a mixture of approx. 10 plants were used per family.

\section{Assessment of the developmental stage}

The following scale was applied: Stage $0=$ vegetative; stage $1=$ first buds visible; stage $2=$ first bud $>1 \mathrm{~mm}$, flowering shoot elongating; stage $3=1-3$ flowers open; stage $4=4-10$ flowers open; stage $5=$ more than 10 flowers open; stage $6=1-3$ siliques mature; stage $7=4$ 6 siliques mature; stage $8=$ up to $50 \%$ of the siliques on main shoot mature; stage $9=$ more than $50 \%$ of siliques on main shoot mature; stage $10=$ all siliques mature, whole plant yellow.

\section{Generation of the mapping population}

A Bur-0 O $\times$ Ler-0 Ơ cross was performed. A single F1plant was selfed and $243 \mathrm{~F} 2$-plants were raised from which leaf material for marker analysis was collected. Each F2-plant was selfed again and F3-seeds were collected from each F2-plant separately. Parents, F1 and F3-families were used for infestation experiments.

\section{Marker analysis}

The markers used in the present study were identified from different sources. Twenty eight previously published SSR markers [33,34] were used. Eleven sequencecharacterised (SCAR) markers were developed for the present study (see Additional File 1) by exploiting length polymorphisms in the sequences of Ler-1 and Bur-0 [35] using the MSQT query tool [36]. The erecta mutation present in Ler [37] was used as a morphological marker. 
DNA of shock-frozen rosette leaves was extracted with the CTAB method [38]. The markers were amplified using PCR $\left(94^{\circ} \mathrm{C}\right.$ for $1 \mathrm{~min}, 40$ cycles of $94^{\circ} \mathrm{C}$ for $15 \mathrm{~s}$, 50 or $55^{\circ} \mathrm{C}$ for $15 \mathrm{~s}, 72^{\circ} \mathrm{C}$ for $30 \mathrm{~s}$ ). PCR products were separated on $3.5-4 \%(\mathrm{w} / \mathrm{v})$ agarose gels (Agarose NEEO Ultra from Roth).

\section{QTL analysis}

A linkage map of 40 markers polymorphic for the parental lines was constructed and allele frequencies of each marker were analysed for significant deviations from the 1:2:1 segregation ratio with the program MapDisto [39]. QTL analysis was performed with MapManager QTX 20b [40] using the Kosambi function. Simple interval mapping was performed scanning the genome in $1 \mathrm{cM}$-steps. In cases where one locus was especially prominent, composite interval mapping using the most significant locus as a background for the calculation of further QTL was performed. MapManager QTX gives the LRS (likelihood ratio statistic) value to assess the probability of a false positive, where LRS $=4.6 \times$ LOD [41]. LRS significance threshold values for the $37 \%$ (putative), 95\% (significant) and 99.9\% (highly significant) genome-wide confidence level were determined by permutation tests with 10,000 permutations. The position of a QTL was determined as a peak LRS score exceeding a certain confidence level. Confidence intervals for QTL were determined by bootstrap tests which calculate the QTL position for multiple resampled data sets of the original data set. Only those QTL were considered which were detected either in all three F3 experiments or were detected in at least two experiments and beyond the genome-wide 95\%-significance threshold in at least one experiment. For the detection of epistatic interactions the confidence criterion of $\mathrm{p}=$ $10^{-5}$ was set.

\section{Statistical analyses}

Frequency distributions of trait values for all F3-families within an infestation experiment were tested for normality with the Kolmogorow-Smirnow-test and the ShapiroWilk test. For quantitative assessment of the degree of axillary branching, a median test was performed: the number of plants having an axillary branching score above the overall median was recorded for each F3family, F1 and the parental lines. In order to determine the origin of the increasing allele and to estimate the inheritance pattern of a certain QTL, ANOVA and multiple comparisons (Tukey test) were performed on trait values between families which were maternal, paternal or heterozygous at the marker site closest to the QTL of interest. For those traits which did not show a normal distribution, the results were confirmed with the nonparametric Mann-Whitney-U-test. The U-test was also used to compare the values from the median test quantifying basal axillary branching. Heritability for traits which could be measured for single plants was calculated as $\mathrm{H}^{2}=\mathrm{V}_{\mathrm{G}} / \mathrm{V}_{\mathrm{G}}+\mathrm{V}_{\mathrm{E}}$ using variance components obtained through MINQUE, where $\mathrm{V}_{\mathrm{G}}$ is the genetic variance and $V_{E}$ is the environmental variance [42]. For traits with single values per F3-family, like the degree of systemic colonisation or axillary branching scores, heritability was calculated after the F3P method [43] using the formula $\mathrm{H}^{2}=\mathrm{V}_{\mathrm{F} 3-\mathrm{P}} / \mathrm{V}_{\mathrm{F} 3}$, where $\mathrm{V}_{\mathrm{F} 3}$ is the variance between the F3-families and ${ }_{P}$ is the average variance of a trait within the parental lines. To test for genotype $x$ experiment-interactions, two-factorial ANOVA was performed for all traits with single-plant values. SPSS Statistics 17.0 (SPSS Inc., Chicago) was used for all statistical analyses.

\section{Results}

\section{Establishment of a linkage map for (BurXLer) mapping populations}

The A. thaliana ecotypes Landsberg erecta (Ler) and Burren (Bur) were found to differ in their reactions towards challenge with the vascular pathogen $V$. longisporum in various aspects (see below). To identify chromosomal regions that control the traits, a (Bur $\times$ Ler) map based on 28 simple sequence repeat (SSR) markers, 11 sequence-characterised (SCAR) markers and one morphological marker (erecta) was established. The marker locations on the physical map of the Arabidopsis Genome Iniative (AGI) are known for most markers and the marker order of the linkage map was as predicted according to the physical positions. The SCAR markers were developed for the present mapping population from known insertions or deletions in the Bur and Ler genomes and are presented in Additional File 1. In total the map spanned $368.2 \mathrm{cM}$, with an average marker spacing of 9.4 cM (see Additional File 2). The largest distance between adjacent markers was $24.4 \mathrm{cM}$. Segregation distortion was only observed at marker EH3-1 on chromosome 3.

\section{Multiple QTL control resistance to systemic spread in $A$. thaliana ecotype Bur}

Significant differences in the extent of systemic spread of $V$. longisporum in the shoot system were found between the $A$. thaliana ecotypes Ler and Bur in greenhouse infestation experiments. The degree of systemic colonisation was measured as the percentage of apical shoot segments colonised by the fungus compared to the total number of shoot segments. When explanted on malt agar plates, apical shoot segments of inoculated Ler plants showed fungal outgrowth to a much higher percentage than those of ecotype Bur at the onset of fruit maturation (Figure 1), reflecting a difference in the 

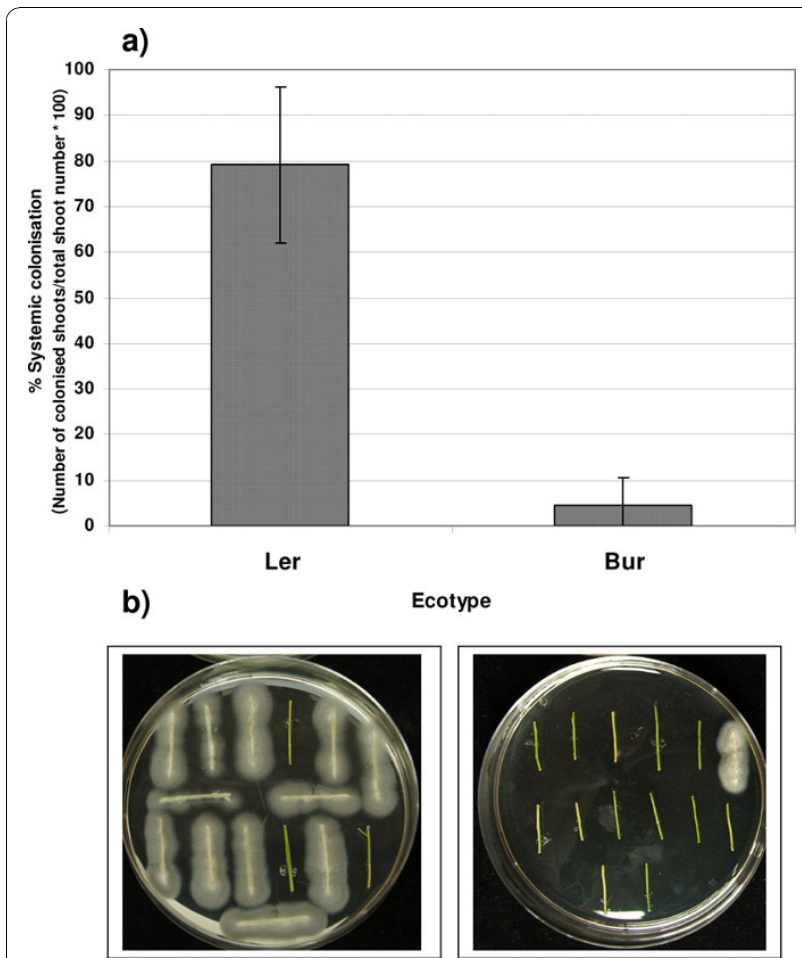

Figure 1 Degree of systemic colonisation by $V$. longisporum in Ler and Bur at the onset of maturity. a) Percentage of plants with colonised apical shoot segments $(100 \%=$ total number of tested plants). Means of nine experiments are shown, bars denote standard deviations. b) Ler shoot segments (left) showing heavy outgrowth of $V$. longisporum, sparse outgrowth from Bur shoot segments (right).

probability of viable conidiospores reaching the apical part of the shoot system. To study the progress of infection during plant development, the time course of systemic spread was analysed for both ecotypes. In addition, the amount of fungal DNA in apical shoot segments was measured by qPCR. In Ler, shoot colonisation started during the early flowering stages and reached highest values during fruit maturation, whereas the colonisation levels in Bur were low throughout all developmental stages (Figure 2). The onset of fruit maturation was chosen as the most appropriate time point to determine the degree of systemic colonisation in all subsequent infestation experiments because by then colonisation was already advanced in susceptible lines and the shoot tissue was still viable enough so that no saprophytic growth could take place. Since Bur develops more slowly than Ler, and in routine experiments both ecotypes were inoculated at the same time, the possibility had to be considered that the time point of inoculation relative to the onset of flowering was responsible for the difference in systemic spread. To test this hypothesis, both ecotypes were inoculated at specific developmental stages. Ler always showed high

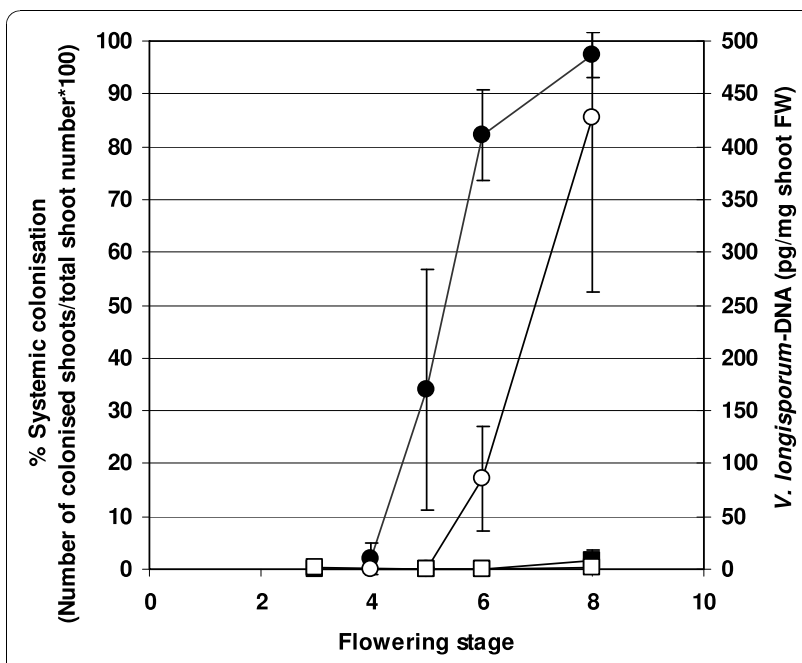

Figure 2 Systemic colonisation of Ler and Bur by $V$. longisporum in the course of plant development. Percentage of colonised plants (closed symbols) and fungal DNA-content in apical shoot segments (open symbols) in Ler (circles) and Bur (squares) at different developmental stages. Developmental stages: $3=1-3$ flowers open, $4=4-10$ flowers open, $5=$ more than 10 flowers open, $6=$ up to 3 siliques mature, $7=4-6$ siliques mature, $8=$ up to $50 \%$ of siliques on main shoot mature. $N=4$ (Bur) or 5 (Ler), bars denote standard deviations.

colonisation rates, whereas Bur always showed low colonisation rates (data not shown). Thus the difference in systemic spread between the ecotypes was not caused by differences in the developmental stage during inoculation. It was further tested whether the difference in systemic spread could also be observed when plants were inoculated without prior wounding of the roots. The colonisation rates in this experiment were $0 \%$ for Bur and $90 \%$ for Ler and thus very similar to the rates in experiments with dip inoculation of injured roots. For QTL-mapping of loci affecting systemic spread, the percentage of plants showing colonised shoot segments was recorded in F3-families originating from individual F2plants in three infestation experiments (E1-E3). For E3, data from qPCR quantifying the amount of VerticilliumDNA in the shoot samples were also available. Means of $V$. longisporum-DNA amounts determined by qPCR were significantly correlated with the colonisation values of the malt agar test in E3 (Figure 3). Broad-sense heritability $\left(\mathrm{H}^{2}\right)$ of the trait systemic colonisation was moderate to high when data of the malt agar test were used. With the qPCR values available for E3, $\mathrm{H}^{2}$ was much lower (Table 1). Frequency distributions of colonisation data in each experiment were multi-modal and suggest that several QTL are involved in controlling this trait (Additional File 3).

Four QTL that meet the criteria of significance and/or reproducibility applied in the present study were 


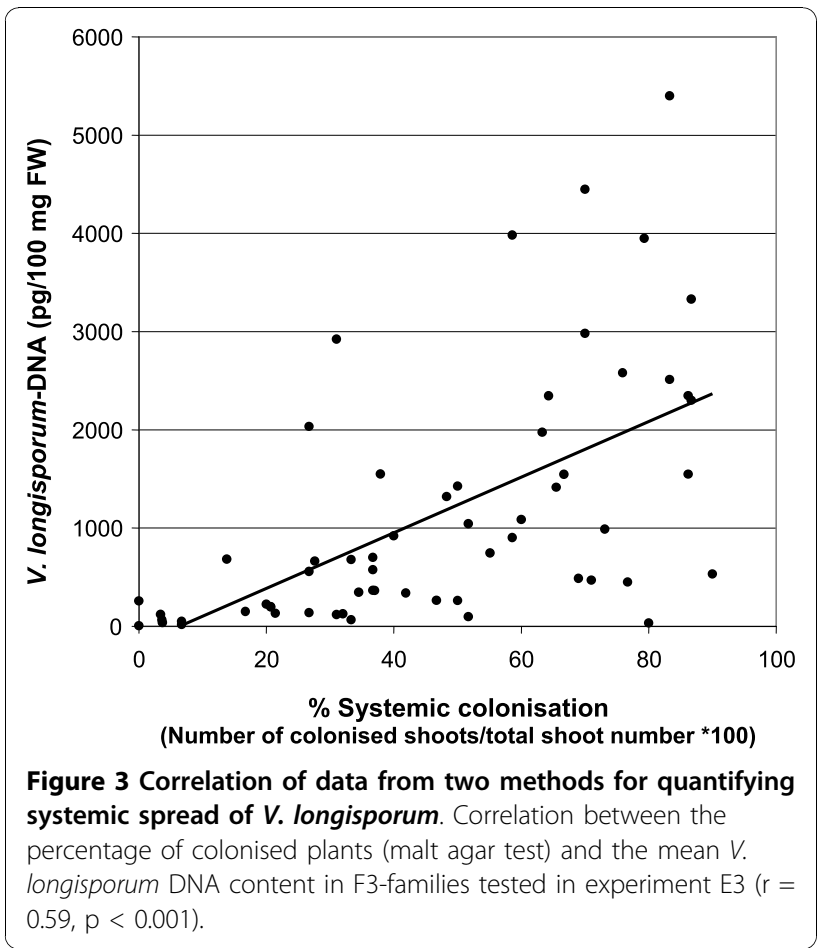

detected by interval mapping of the trait systemic colonisation as determined by the malt agar test (Figure 4, Table 2). The QTL with the strongest effect (vec1) was detected on chromosome 2 near the morphological marker erecta. Three QTL of lesser effect (vec2, vec3 and $v e c 4$ ) were detected near the markers nga 8 and ciw7 on chromosome 4 and near marker nga 139 on chromosome 5 , respectively. vec 2 and vec 4 were detected in all three infestation experiments, whereas $v e c 1$ and vec 3 could be reproduced in two of three experiments. Results from the most representative experiment for each QTL were chosen (see also Additional File 4) and displayed in Figure 4 and Table 2. All vec alleles increasing the degree of colonisation came from ecotype Ler. $v e c 1, v e c 2$ and $v e c 3$ were recessive, vec 4 showed intermediate inheritance (Table 2). This corresponds with low to moderate colonisation rates in the F1-generation (see Additional File 3). When QTL-mapping was performed with fungal DNA contents in experiment E3, two QTL could be detected whose confidence intervals overlapped with $v e c 1$ and $v e c 3$, respectively (Figure 4, Table 2). The peak LRS values of vec1 and vec3, however, were lower when qPCR data were applied (Table 2 , Additional file 4). vec 2 and vec4, which were only detected at the putative level with the re-isolation method in E3, could not be detected with the qPCR values. Epistatic interactions were analysed with MapManager QTX. One epistatic interaction was detected in experiment E3 between marker erecta, which is close to
Table 1 Broad-sense heritability for Verticillium-related traits in the $A$. thaliana (BurXLer) F2/F3 mapping population

\begin{tabular}{|c|c|c|c|}
\hline Trait & Exp. & $\mathrm{H}^{2}$ & Method \\
\hline \multirow{3}{*}{$\begin{array}{l}\text { Degree of Verticillium colonisation (vec; malt agar } \\
\text { test; number of colonised shoot segments/total } \\
\text { number of shoot segments in\%) }\end{array}$} & E1 & 0.58 & F3P \\
\hline & E2 & 0.59 & \\
\hline & E3 & 0.76 & \\
\hline $\begin{array}{l}\text { Degree of Verticillium colonisation (vec a; real-time } \\
\text { qPCR; pg Verticillium DNA/100 mg shoot fresh } \\
\text { weight) }\end{array}$ & E3 & 0.45 & VCA \\
\hline \multirow{3}{*}{$\begin{array}{l}\text { Development time }(d t \text {; days from germination to } \\
\text { maturity in mock-inoculated plants) }\end{array}$} & E1 & 0.46 & VCA \\
\hline & E2 & 0.49 & \\
\hline & E3 & 0.62 & \\
\hline \multirow[t]{3}{*}{ Shoot fresh weight (g) } & E1 & 0.21 & VCA \\
\hline & E2 & 0.40 & \\
\hline & E3 & 0.49 & \\
\hline \multirow{3}{*}{$\begin{array}{l}\text { Stunting resistance (stre; shoot height of } \\
\text { Verticillium-inoculated plants in } \mathrm{cm} \text { ) }\end{array}$} & E1 & 0.35 & VCA \\
\hline & E2 & 0.49 & \\
\hline & E3 & 0.39 & \\
\hline \multirow{3}{*}{$\begin{array}{l}\text { Verticillium-induced axillary branching ( } \mathrm{vab} \text {; } \\
\text { number of plants with a branching score above } \\
\text { the overall median of Verticillium-inoculated } \\
\text { plants) }\end{array}$} & E1 & 0.54 & F3P \\
\hline & E2 & 0.67 & \\
\hline & E3 & 0.82 & \\
\hline
\end{tabular}

Broad-sense heritability $\left(\mathrm{H}^{2}\right)$ of traits for each experiment (exp.) was calculated either with variance component analysis (VCA) [42] or with the F3P method [43] as indicated.

$v e c 1$, and marker ciw6 on chromosome 4, which is not within the confidence interval of any of the vec QTL reported here. This interaction was not detected in E1 or E2 or by qPCR.

\section{QTL controlling systemic spread partly overlap with QTL} for development time

The degree of colonisation was negatively correlated with the duration of development among F3-families in all three experiments (Table 3). QTL for development time were therefore mapped by recording the number of days from germination to the maturation of the first siliques in mock-inoculated plants. Bur and Ler differed in the duration of their developmental cycle, reflecting the difference in flowering time. The time until the plants reached maturity was always longer for Bur than for Ler, but for both ecotypes it varied considerably with the season in which the experiment was performed. In summer experiments, the fastest development for Ler was 32 days to maturity, for Bur 38 days. In winter, the longest period for both ecotypes was 60 and 72 days to maturity respectively. The segregating F3-population showed transgressive variation in one direction: No F3-family had a 


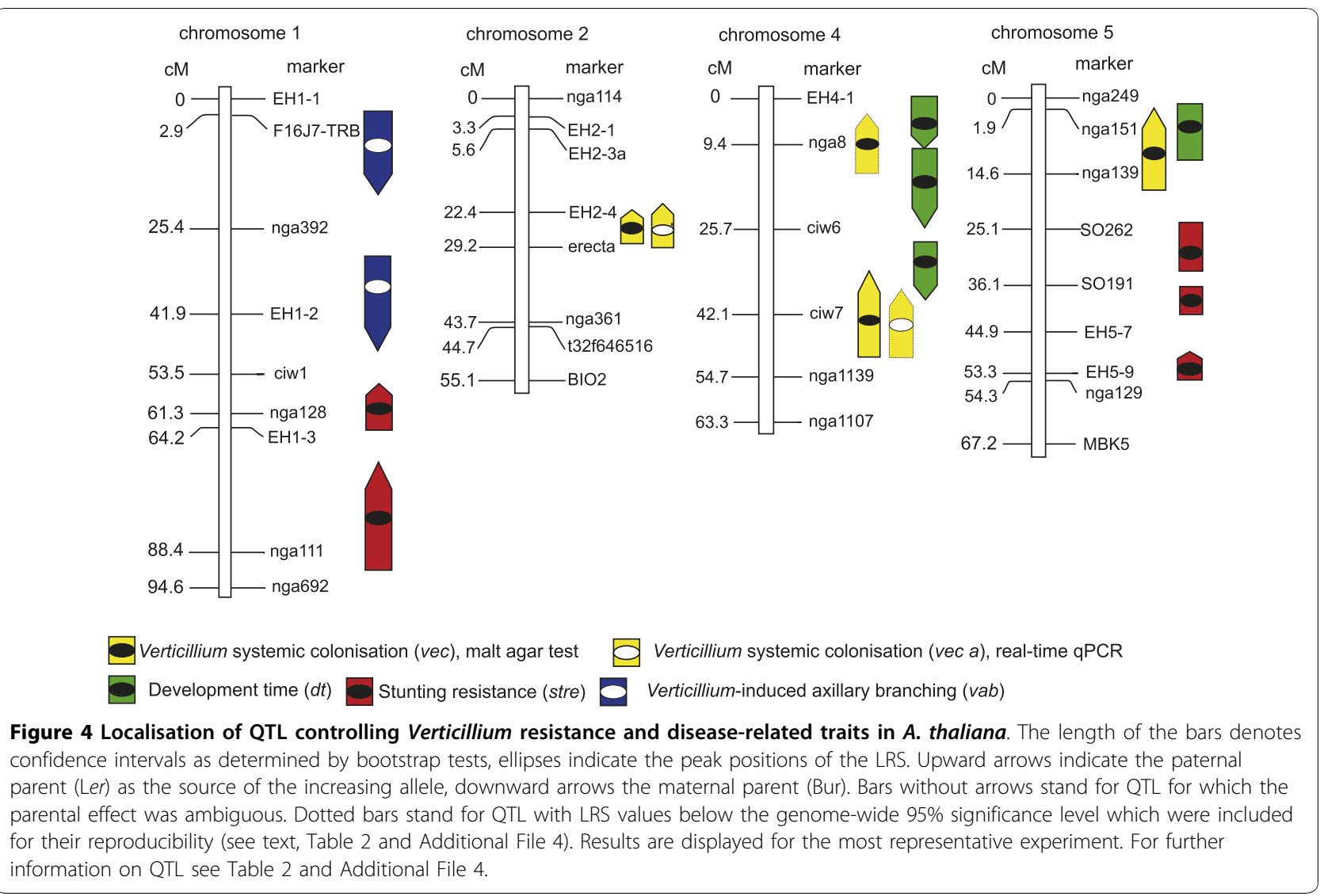

shorter mean development time than Ler, but up to $40 \%$ of all F3-families and, in two experiments, also the F1generation showed a slower development than Bur (Additional File 3). Family means of development time for the controls were normally distributed in all three experiments (Additional File 3). Broad sense heritability of the trait was moderate (Table 1). Development time was significantly affected by genotype and by the experiment, and significant interactions between genotype and experiment were found (Additional File 5). Three QTL controlling development time were found in the top half of chromosome 4 ( $d t 1-d t 3)$, and one QTL was detected near marker nga151 on chromosome 5 ( $d t 4$; Figure 4, Table 2). $d t 1$ and $d t 4$ were detected in every experiment, $d t 2$ and $d t 3$ only in two of three F3 experiments (Additional File 4). The QTL with the strongest effect, $d t 1$, was mapped near marker nga8 at the top of chromosome 4 and thus co-localised with a major colonisation QTL, $v e c 2$. For the three $d t \mathrm{QTL}$ on chromosome 4 , the alleles delaying development came from Bur, whereas for $d t 4$, families originating from heterozygous F2-plants flowered significantly later than either maternal or paternal homozygous families. An epistatic interaction could be detected in E1 and E2 between marker EH4-1 on chromosome 4 , which is in the confidence interval of $d t 1$, and marker SO191 on chromosome 5. In E2, a second interaction was detected between EH4-1 and nga151, the latter being within the confidence interval of $d t 4$ on chromosome 5.

$V$. longisporum-treatment significantly accelerated the development in many F3-families. Acceleration (mean days to maturity controls $_{\text {- mean days to maturity }}$ inoculated $_{\text {) }}$ was closely correlated with the duration of the developmental cycle in controls (Table 3), i.e. slowly developing families were more accelerated after infection than fast families. The correlation was much weaker with the days to maturity of the inoculated variant $\left(r=0.39^{* * *}\right.$ in E1). QTL controlling developmental acceleration, however, could not be detected.

\section{Stunting depended on development time and season}

Stunting was a particularly striking disease symptom (Figure 5). Stunting resistance was recorded in two different ways in the present study: 1) As the absolute plant height at the onset of maturity of inoculated plants, and 2) as performance (mean height inoculated $_{\text {mean height }}$ control $\times 100$ ). The trait performance compensates for the fact that plants carrying a homozygous erecta mutation have a much lower plant height than plants carrying a wild type erecta allele. The performance of Ler and Bur varied between 
Table 2 QTL detected for Verticillium-related traits in the A. thaliana (BurXLer) F2/F3 mapping population

\begin{tabular}{|c|c|c|c|c|c|c|c|c|c|c|c|}
\hline \multirow[t]{2}{*}{ Trait } & \multirow[t]{2}{*}{ QTL } & \multirow[t]{2}{*}{ Exp. } & \multirow[t]{2}{*}{ Chr. } & \multirow{2}{*}{$\begin{array}{l}\text { Peak } \\
\text { pos. } \\
\text { (cM) }\end{array}$} & \multirow[t]{2}{*}{$\begin{array}{l}\text { Nearest } \\
\text { marker }\end{array}$} & \multirow[t]{2}{*}{ LRS } & \multirow[t]{2}{*}{ LOD } & \multirow{2}{*}{$\begin{array}{l}\text { Explained } \\
\text { trait } \\
\text { variance }\end{array}$} & \multicolumn{3}{|c|}{$\begin{array}{l}\text { Mean } \pm \text { SD (or median) for F3-families with } \\
\text { alleles from: }\end{array}$} \\
\hline & & & & & & & & & Bur & Heterozygous & Ler \\
\hline \multirow{4}{*}{$\begin{array}{l}\text { Degree of Verticillium } \\
\text { colonisation (vec; malt agar test; } \\
\text { number of colonised shoot } \\
\text { segments/total number of } \\
\text { shoot segments in\%) }\end{array}$} & vecl & E1 & 2 & 26 & erecta & $21.2^{* *}$ & 4.6 & $31 \%$ & $20.4 \pm 13.8^{\mathrm{a}}$ & $18.4 \pm 14.5^{\mathrm{a}}$ & $43.8 \pm 27.1^{b}$ \\
\hline & vec2 & E2 & 4 & 10 & nga8 & $9.4^{*}$ & 2.0 & $11 \%$ & $21.2 \pm 17.2^{\mathrm{a}}$ & $26.3 \pm 21.8^{\mathrm{a}}$ & $41.8 \pm 15.8^{b}$ \\
\hline & vec3 & E3 & 4 & 45 & ciw7 & $17.0^{* *}$ & 3.7 & $18 \%$ & $32.0 \pm 29.2^{\mathrm{a}}$ & $41.0 \pm 20.5^{a}$ & $65.2 \pm 21.5^{b}$ \\
\hline & vec4 & E1 & 5 & 11 & nga139 & $20.7^{* *}$ & 4.5 & $31 \%$ & $7.7 \pm 6.0^{a}$ & $23.2 \pm 16.5^{b}$ & $42.0 \pm 24.1^{c}$ \\
\hline \multirow{2}{*}{$\begin{array}{l}\text { Degree of Verticillium } \\
\text { colonisation (vec a; real-time } \\
\text { qPCR; pg Verticillium DNA/100 } \\
\text { mg shoot fresh weight) }\end{array}$} & vecl a & E3 & 2 & 27 & erecta & $14.2^{* *}$ & 3.1 & $20 \%$ & $764 \pm 1071^{a}$ & $1061 \pm 1035^{a}$ & $1994 \pm 1588^{b}$ \\
\hline & vec3 a & E3 & 4 & 47 & ciw7 & $13.4^{*}$ & 2.9 & $13 \%$ & $976 \pm 1162^{a}$ & $751 \pm 741^{a}$ & $2015 \pm 1615^{b}$ \\
\hline \multirow{4}{*}{$\begin{array}{l}\text { Development time ( } d t \text {; days } \\
\text { from germination to maturity in } \\
\text { mock-inoculated plants) }\end{array}$} & $d t 1$ & E1 & 4 & 5 & nga8 & $18.8^{* *}$ & 4.1 & $29 \%$ & $64.4 \pm 7.5^{a}$ & $58.6 \pm 7.4^{a, b}$ & $54.3 \pm 3.8^{b}$ \\
\hline & $d t 2$ & E1 & 4 & 16 & nga8 & $18.2^{* *}$ & 4.0 & $28 \%$ & $64.4 \pm 7.5^{\mathrm{a}}$ & $58.6 \pm 7.4^{a, b}$ & $54.3 \pm 3.8^{b}$ \\
\hline & $d t 3$ & E1 & 4 & 33 & ciw6 & $17.2^{* *}$ & 3.7 & $26 \%$ & $63.3 \pm 7.2^{\mathrm{a}}$ & $58.0 \pm 7.2^{a, b}$ & $54.5 \pm 4.7^{b}$ \\
\hline & $d t 4$ & E2 & 5 & 5 & nga151 & $17.0^{* *}$ & 3.7 & $24 \%$ & $50.3 \pm 3.1^{\mathrm{a}}$ & $55.0 \pm 4.8^{b}$ & $49.8 \pm 5.7^{a}$ \\
\hline \multirow{5}{*}{$\begin{array}{l}\text { Stunting resistance (stre; shoot } \\
\text { height of Verticillium-inoculated } \\
\text { plants in } \mathrm{cm} \text { ) }\end{array}$} & strel & E1 & 1 & 79 & nga111 & $32.5^{* * *}$ & 7.1 & $51 \%$ & $10.9 \pm 2.2^{\mathrm{a}}$ & $16.1 \pm 3.8^{b}$ & $20.2 \pm 4.3^{c}$ \\
\hline & stre2 & E1 & 1 & 59 & nga128 & $22.2^{* *}$ & 4.8 & $39 \%$ & $11.1 \pm 2.3^{\mathrm{a}}$ & $17.4 \pm 4.5^{b}$ & $17.8 \pm 3.9^{b}$ \\
\hline & stre3 & E3 & 5 & 31 & SO191 & $20.4^{* *}$ & 4.4 & $39 \%$ & $28.7 \pm 3.1^{\mathrm{a}, \mathrm{b}}$ & $24.7 \pm 5.3^{\mathrm{a}}$ & $32.7 \pm 3.5^{b}$ \\
\hline & stre4 & E3 & 5 & 39 & SO191 & $20.9^{* *}$ & 4.5 & $40 \%$ & $28.7 \pm 3.1^{a, b}$ & $24.7 \pm 5.3^{a}$ & $32.7 \pm 3.5^{b}$ \\
\hline & stre5 & E3 & 5 & 53 & nga129 & $15.8^{* *}$ & 3.4 & $32 \%$ & $26.5 \pm 3.1^{\mathrm{a}}$ & $25.7 \pm 5.5^{\mathrm{a}}$ & $33.5 \pm 3.2^{b}$ \\
\hline \multirow{3}{*}{$\begin{array}{l}\text { Verticillium-induced axillary } \\
\text { branching (vab; number of } \\
\text { plants with a branching score } \\
\text { above the overall median of } \\
\text { Verticillium-inoculated plants) }\end{array}$} & vab1 & E1 & 1 & 9 & F16J7- & $28.1^{* * *}$ & 6.1 & $39 \%$ & $20^{a}$ & $13^{\mathrm{b}}$ & $10^{\mathrm{b}}$ \\
\hline & & & & & TRB & & & & & & \\
\hline & vab2 & E1 & 1 & 34 & $\mathrm{EH} 1-2$ & $22.2^{* *}$ & 4.8 & $33 \%$ & $20^{\mathrm{a}}$ & $12^{a, b}$ & $10.5^{\mathrm{b}}$ \\
\hline
\end{tabular}

LRS $=$ likelihood ratio statistic. Asterisks denote genome-wide significance thresholds determined by permutation tests as follows: ${ }^{*} 37 \%$, $* * 95 \%, * * * 99.9 \%$ In each row, values with different letters differ significantly with at least $p<0.05$. ANOVA and tukey tests were used for metric values; differences of values that were not normally distributed were confirmed with pairwise Mann-Whitney-U-tests. For axillary branching scores the median is given; values were compared pairwise with U-tests. Results are displayed for the most representative experiment (exp.). For reproducibility see Additional file 4.

Table 3 Correlations between resistance and developmental traits in F3-families

\begin{tabular}{|c|c|c|}
\hline Traits & Exp. & $r$ \\
\hline \multirow[t]{3}{*}{ Degree of Verticillium colonisation vs. days to maturity in mock-inoculated plants } & E1 & $-0.42^{* *}$ \\
\hline & E2 & $-0.73^{* * *}$ \\
\hline & E3 & $-0.62^{* * *}$ \\
\hline \multirow[t]{3}{*}{ Verticillium-induced difference in days to maturity vs. days to maturity in mock-inoculated plants } & E1 & $0.74^{* * *}$ \\
\hline & E2 & $0.61^{* * *}$ \\
\hline & E3 & $0.68^{* * *}$ \\
\hline \multirow[t]{3}{*}{ Performance 'Height' vs. days to maturity in mock-inoculated plants } & E1 & $-0.67^{* * *}$ \\
\hline & E2 & $-0.43^{* * *}$ \\
\hline & E3 & $-0.47^{* * *}$ \\
\hline \multirow[t]{3}{*}{ Performance 'Height' vs. degree of Verticillium colonisation } & E1 & $0.47^{* * *}$ \\
\hline & E2 & $0.26^{*}$ \\
\hline & E3 & $0.27^{*}$ \\
\hline
\end{tabular}

Exp. $=$ experiment, $r=$ Pearson correlation coefficient. Asterisks denote error probability $\left({ }^{*} \alpha=5 \%,{ }^{* *} \alpha=1 \%,{ }^{* * *} \alpha=0.1 \%\right)$. 


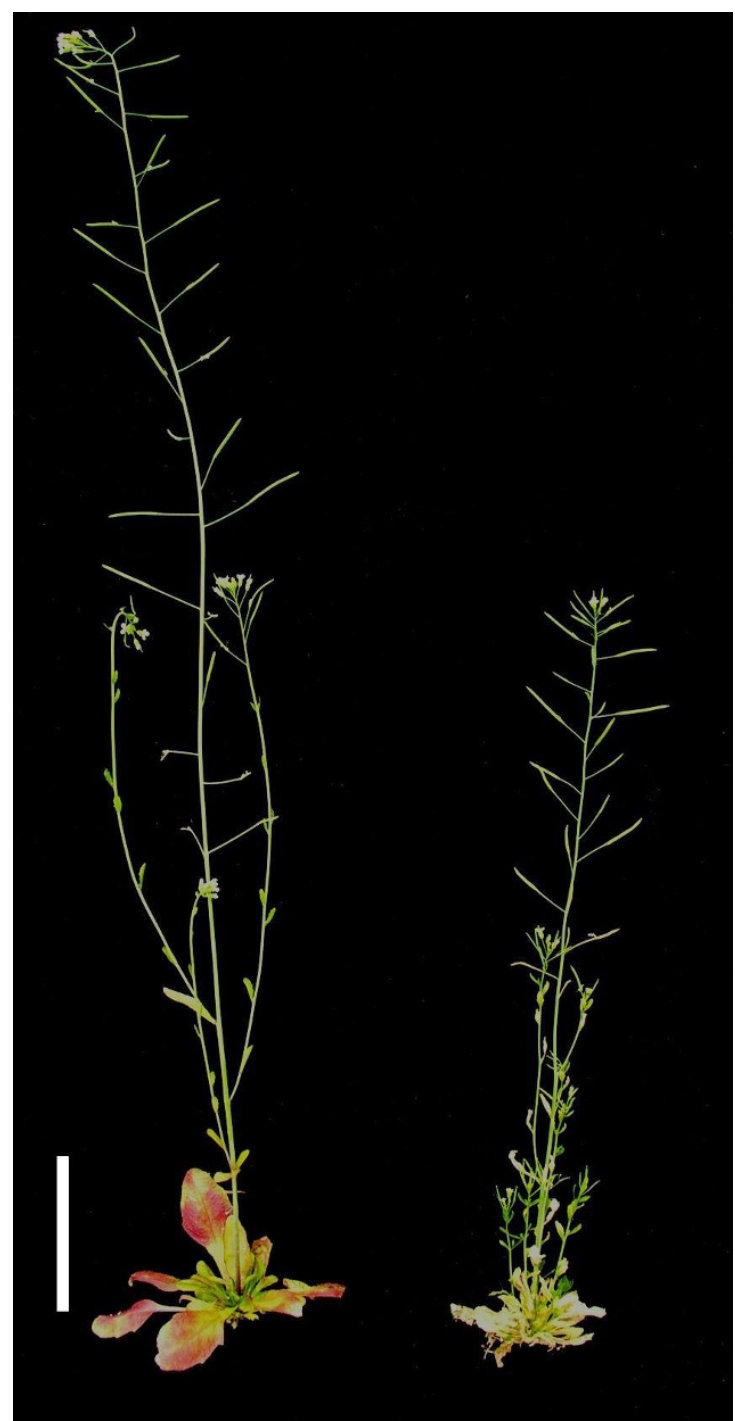

Figure $5 \mathrm{~V}$. longisporum-induced stunting and axillary branching in $\boldsymbol{A}$. thaliana ecotype Bur. Inoculated plant (right) reached $57 \%$ of the height of mock-inoculated plant (left) at the onset of fruit maturation and showed bolting of shoots from the axils of the rosette leaves. $B a r=5 \mathrm{~cm}$.

different experiments. Bur showed much more variation across different experiments than Ler (Figure 6). The performance was significantly negatively correlated with the development time that differed between the experiments (Figure 6). While Bur performed better than Ler when maturity was reached early, it showed much more stunting caused by $V$. longisporum when the development was prolonged due to season. The same effect was observed when the performance of F3-families was correlated with their mean development time: Early-flowering families performed better than late-flowering lines (Table 3). The performance showed a weak positive correlation with

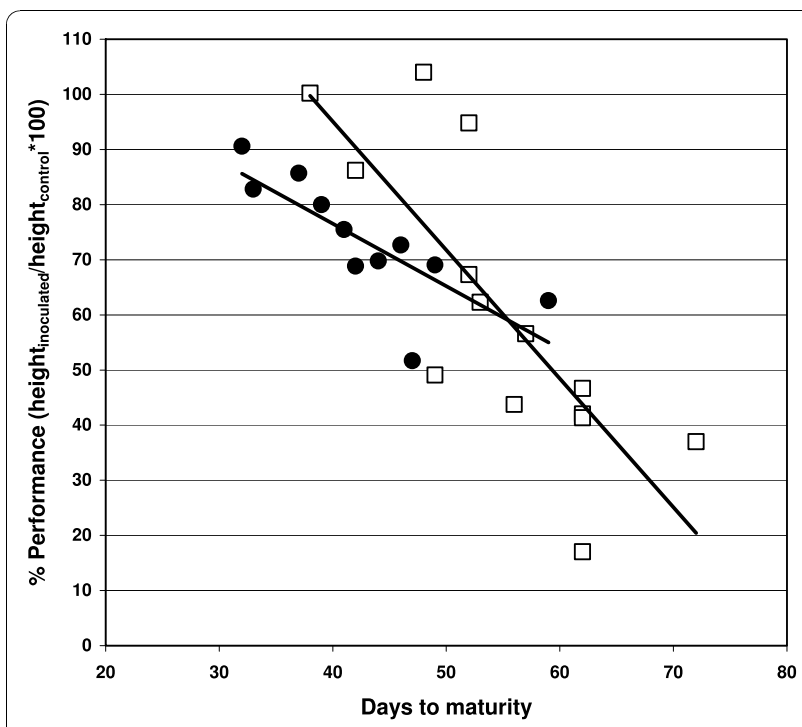

Figure 6 Correlation of performance with development time in Ler and Bur. Performance (\%) $=$ Height $_{\text {inoculated }} /$ Height $_{\text {control }} \times 100$; Ecotypes Ler (circles) and Bur (squares) are illustrated. Each data point represents a separate infestation experiment. Experiments were performed at different seasons over three years. Ler: $r=-0.79$, $p=0.004$; Bur: $r=-0.79, p<0.001$.

colonisation rates in all three F3-experiments (Table 2), meaning that severely colonised lines were less stunted than colonisation-resistant lines. This relationship was even more distinct regarding the absolute plant height of inoculated F3-families $(r=0.62$ in E1; erecta plants were excluded). As another method to assess stunting, the fresh weight for each plant was recorded. However, this trait varied to a considerably higher degree than plant height due to differences in branching patterns among plants and small-scale variation in nutrient supply and humidity of the soil. In a two-factorial ANOVA, no significant genotype effect on the fresh weight could be detected, whereas the experiment significantly explained fresh weight variance as well as genotypexexperiment-interaction (Additional File 5). As expected from traits that are strongly influenced by environmental factors, broad-sense heritability for both plant height and fresh weight was moderate to low (Table 1). No reproducible QTL controlling either the performance or the fresh weight were detected.

As a further approach to identify QTL controlling stunting resistance in the mapping population, we used mean height values of inoculated plants per family after excluding plants with erecta phenotype. Significant genotypexexperiment-interactions existed for this trait (Additional File 5). In accordance with the strong difference in stunting between seasons, the QTL showed differences in significance level between different infestation experiments. A highly significant locus (stre1) 
could be detected near marker nga111 on chromosome 1. A second significant locus was identified on the same chromosome near marker nga128 (stre2). These loci were most significant in the winter experiment E1, but could also be detected in the late spring experiment E3. In E3, three significant QTL controlling the height of Verticillium-infected plants (stre3, stre4 and stre5) were detected on chromosome 5 (Figure 4, Table 2). stre 3 and stre 4 could be reproduced at the putative level in both other experiments and stre 5 could be reproduced in experiment E1 (Additional file 4). For stre1 and stre 2 on chromosome 1 , the alleles increasing the plant height came from Ler, which is in accordance with the finding that Ler plants were more resistant to stunting than Bur plants under winter conditions. Whereas stre1 showed intermediary inheritance (families from F2 plants heterozygous at marker nga111 show an intermediate phenotype), the stre 2 allele from Ler was dominant. For stre3 and 4, plants homozygous for the Ler alleles were higher than plants that were homozygous for Bur alleles at these loci, but plants that were heterozygous at these loci showed the most extreme stunting phenotype, indicating a complex inheritance of the trait in this region. For stre5, the increasing allele came from Ler and was recessive (Table 2). All QTL for stunting resistance were absent when mock-inoculated plants were analysed, implying these QTL are not general regulators of plant height but selectively conferred stunting resistance under $V$. longisporum pressure. Apart from erecta, no reproducible locus controlling plant height in the mockinoculated plants could be identified with the present data set.

\section{Two loci on chromosome 1 control Verticillium-induced bolting of axillary buds}

$V$. longisporum increased the bolting of basal axillary buds in Bur. In mock-inoculated plants, typically up to two axillary shoots could be observed, whereas in inoculated plants, often more than five shoots emerged from the axillary buds of the rosette leaves (Figure 5). This phenotype could not be observed in Ler. In Figure 7 the branching patterns for both parental ecotypes with or without $V$. longisporum-inoculation are compared. The F3-families showed segregation for this trait. The number of plants with a branching score above the overall median was calculated for each F3-family. QTL mapping resulted in two loci on the upper arm of chromosome 1 (vab1 and vab2) controlling this trait (Figure 4, Table 2). vab1 was highly significant in experiment E1, significant in E2 and putative in E3. vab2 was significant in E1 and E3, but absent in E2. Alleles increasing axillary branching originated from Bur and were recessive. Accordingly, this phenotype was never observed in F1 plants.

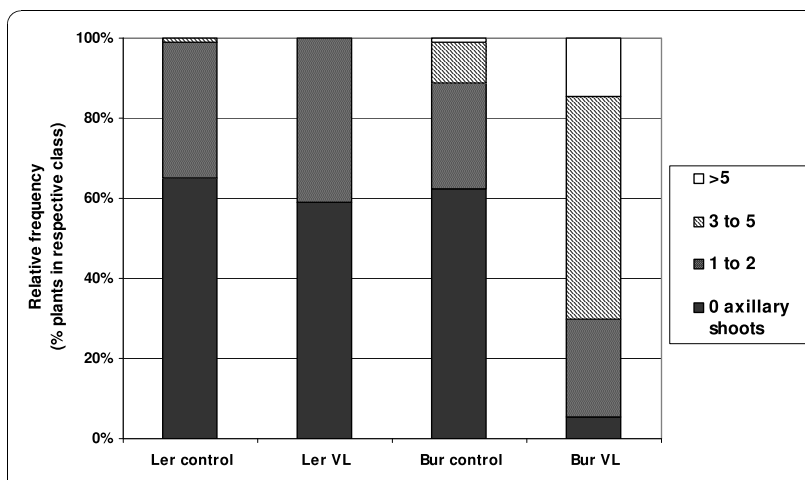

Figure 7 Proportion of increased axillary branching in Ler and Bur. According to their number of axillary rosette shoots plants were assigned to classes ranging from 0 (no axillary rosette shoots) to 3 (more than 5 axillary rosette shoots). No significant difference existed between inoculated (VL) and mock-inoculated (control) Ler plants $\left(\chi^{2}=2.42, p=0.32\right)$. Inoculated and mock-inoculated Bur plants differed significantly $\left(\chi^{2}=93.65, p<0.0001\right) . N=90$ per column, pooled data of three experiments.

\section{Discussion}

By using a mapping approach it was possible to show that the complex Verticillium syndrome in A. thaliana is controlled by multiple genes which affect different disease and/or resistance traits separately. Stunting resistance did not depend on resistance to the systemic spread of the pathogen, and both traits were controlled by different QTL. Verticillium pathogenesis and disease reactions showed a complex cross-talk with host development and were influenced by environmental factors in greenhouse experiments.

Genetic differences in resistance among natural $A$. thaliana-populations to Verticillium systemic spread have not yet been reported in the literature. In a previous study, colonisation rates were determined as colony-forming units obtained by plating macerated tissue of whole plants [29], but no differences between the ecotypes Col-0 and C24 were found before the onset of extensive tissue death. These ecotypes however differed only marginally in their colonisation rates in the shoot apex [44]. The present study shows that the ecotypes Bur and Ler differ considerably in the degree to which the apical part of the shoot is colonised by $V$. longisporum. The results were reproducible in independent experiments and allowed the detection of QTL controlling the systemic spread of the pathogen. Four vec QTL detected in the present study accounted for $91 \%$ and $86 \%$ of the total trait variation in the experiments E1 and E3, where all four vec QTL were detected. The amount of fungal DNA in apical shoot segments correlated significantly with the percentage of colonised shoot segments. The latter reflects the probability of fungal propagules reaching the shoot apex irrespective of the amount of fungal biomass. As expected, the malt 
agar test was more sensitive in detecting low amounts of colonisation, whereas real-time PCR could differentiate between fungal amounts when shoot colonisation rates were high. Factors that affect the amount of fungal biomass in the shoot apex after systemic colonisation can be determined more reliably by quantitative PCR using genetically homogeneous plant material such as RIL. Furthermore, the distribution of fungal biomass in plant tissue is likely to be inhomogeneous. Increasing the amount of material used for the extraction of DNA for real-time PCR is therefore expected to further reduce the variance of fungal biomass estimates [45]. The strongest QTL controlling systemic spread, vec1, explained about $30 \%$ of the trait variation and was located on chromosome 2 near the morphological marker erecta. There is substantial evidence in the literature that ERECTA itself, a receptor-like kinase with leucinerich repeats (EC 2.7.11.30), which is mutated in Ler [37], can play a role in regulating pathogen response in plants $[46,47]$. In loss-of-function erecta mutants callose formation is impaired at the entry sites of the necrotrophic fungus Plectosphaerella cucumerina [47], a process that also plays a role in protecting xylem vessels against Verticillium infection [48,49]. It is, however, also possible that vec1 represents a gene linked to erecta. $v e c 2$ was located near marker nga8 on chromosome 4, in a region where Vet1 had been mapped [29]. Vet1 was reported to confer resistance to Verticillium-induced chlorosis and to act as a negative regulator of flowering. Nothing is known so far about a possible role of Vet 1 in inhibiting systemic spread. Recent work focusing on genes differentially regulated after infection by $V$. longisporum emphasized the role of apoplastic enzymes. In a microarray experiment a high proportion of genes which encode for apoplastic enzymes were identified among the differentially regulated genes in the $A$. thaliana-V. longisporum-pathosystem [50]. Cell wall modifications could be the basis for the inhibition of systemic spread as well as for the stunting phenotype [50]. Upregulated genes in the regions of the vec QTL were At4 g23500, a polygalacturonase (EC 3.2.1.15), and At4 g30460, a glycine-rich protein of unknown function, both localised in the region of vec3. Other mechanisms protecting xylem vessels against $V$. longisporum include apoplastic enzymes like $\beta$-1.3-glucanases (EC 3.2.1.6), peroxidases (EC 1.11.1.-) and endochitinases (EC 3.2.1.14) as reported for Brassica [51]. However, none of the $A$. thaliana genes known to encode cell wall-localised $\beta$-1,3-glucanases [52] nor the A. thaliana homologue of the chitinase up-regulated through $V$. longisporum in Brassica [51] are close to the positions of any vec QTL. Vascular occlusions through deposition of phenolic substances in hypocotyl vessels of oilseed rape were found to accompany the resistance phenotype in certain Brassica lines [5]. Histological investigations in A. thaliana are needed to clarify whether a similar mechanism is responsible for resistance to systemic spread in Bur and if the vec QTL could correspond to genes involved in the respective metabolism. Resistance to systemic spread has been distinguished as an important resistance component also in other vascular pathosystems, such as Fusarium head blight of wheat [53]. QTL were detected that specifically control resistance to systemic spread of Fusarium [54]. Recently, resistance against northern leaf blight in maize could be dissected into penetration resistance and resistance against the spread of Setosphaeria turcica inside the vascular system. Both types of resistance were controlled by different QTL and differed also for their mode-of-action [55]. Dissecting complex disease and resistance phenotypes in a genetic study allows a more in-depth understanding of the genetic and physiological basis of quantitative resistance.

In the present study, resistance to systemic spread in ecotype Bur was associated with slow development, a correlation that became obvious in the F3-families of the (Bur $\times$ Ler) mapping population: Slowly-developing families were less colonised than faster ones. One obvious reason was the overlap of colonisation and developmental QTL. In the present study, the confidence interval of vec 2 overlapped with those of $d t 1$ and $d t 2$ (chromosome 4), vec3 with $d t 3$ (chromosome 4) and vec4 with $d t 4$ (chromosome 5). Two interpretations for this phenomenon are possible. Either the QTL influencing development have pleiotropic effects on systemic spread or they are linked to QTL controlling systemic spread. Distinguishing between linkage and pleiotropy is important for breeding because only in the case of linkage it would be possible to implement resistance without co-selection of a certain developmental type. Enhanced resistance to systemic spread in slowly-developing genotypes was also observed for certain accessions of B. oleracea and B. rapa (E. Diederichsen, unpublished results). The localisation of the $v e c$ and $d t$ QTL in the present study indicates that the correlation between both traits is due to linkage rather than pleiotropic effects of the same gene(s). Candidate genes located in the region of $d t 1$ are $V e t 1$ [29], and fri, which is known to be impaired in Ler [56]. Further studies are required to determine whether $d t 1$, vec 2 and Vet 1 are identical. Flowering genes in the region of $d t 2$ include cry1/hy4, a blue-light receptor [57], det1, a suppressor of photomorphogenesis [58] and ted1, an antagonist of det1 [59]. A known flowering gene in the region of $d t 3$ is $f c a$ at 9.2 $\mathrm{Mb}[60,61]$, which promotes the transition to flowering in the autonomous pathway. $d t 4$ possibly represents two dominant genes delaying development with additive effect originating from different parents. This would 
explain why heterozygotes at marker position nga151 developed significantly more slowly than either maternal or paternal homozygotes. A flowering QTL near marker nga151 was also detected in two different RIL populations [34]. constans (co), fy and flowering locus $C$ (flc) are possible candidates for this QTL. FLC is a potent inhibitor of the transition to flowering integrating the autonomous and the vernalisation pathway [62]. Bur most likely carries a loss-of-function flc allele [63], whilst Ler has a weak $f l c$ allele [64]. The detected epistatic interaction between EH4-1, which is close to fri, and nga151 in the vicinity of $f l c$ may suggest that the pathway nevertheless plays a role in the present mapping population. However, a fri-independent late-flowering QTL from Bur on chromosome 5 was described as well which could correspond to $d t 4$ [63].

Contrary to expectations, high colonisation rates did not coincide with severe disease symptoms such as stunting. Actually a weak positive correlation between colonisation and performance was observed in all three infestation experiments, showing that heavily colonised families were less stunted than sparsely colonised ones. This correlation does not necessarily reflect a causal relationship. Both systemic spread and performance were negatively correlated with development time, a factor that might influence both traits independently. The weaker performance of slowly-developing plants seems to have a physiological basis: In both parental lines Bur and Ler, performance decreased when development was slowed down as a consequence of seasonal changes. An unknown regulatory mechanism might control both stunting severity and developmental velocity differently in interaction with seasonal influences still effective in the greenhouse. Temperature, seasonal changes in light intensity and a higher dosage of blue light in summer are potential factors causing summer/winter differences. Nevertheless, host genetic disposition also plays a role, since Bur shows a much higher difference in performance between summer and winter. In summer experiments with short development times, Bur was consistently less stunted than Ler, whereas the opposite was true in winter experiments. The dependence of quantitative resistance on developmental aspects is a frequently recognised phenomenon $[18,19,65,66]$. Seasonal differences could also be observed in significance levels of stunting resistance QTL. In E1 (started in January 2007), stre 1 and stre 2 were strong, in E3 (started in April 2008) they were present, but only at the putative level. stre 3 to stre 5 were strong in E3, while in E1 and E2 they were weak or absent (Additional File 4). The absence of most stunting resistance QTL in E2 (started in March 2007) might have been due to inhomogeneous soil used in this experiment so that nutritional effects masked genetic effects or seasonal impact on development. The finding that the resistant alleles of the stre QTL on chromosome 1 were of Ler origin is in good accordance with Ler having been more resistant to stunting in winter. However, the situation for stre 3 to stre5 is more complex. Only for stre5, the resistance allele came from Ler. For stre3 and 4, heterozygous families were more susceptible than families carrying either of the parental alleles in the homozygous state. A possible explanation would be that stre 3 and stre 4 contain an array of susceptibility genes of different origin with additive effects. A gene recently found to be involved in Verticillium resistance is rfol, a receptor-like kinase (EC 2.7.11.30) otherwise mediating resistance to Fusarium oxysporum [26]. The rfo1-allele from the $A$. thaliana accession 'Taynuilt' (Ty-0) conferred significant resistance against fresh weight loss caused by Verticillium and is located at the bottom of chromosome 1 at $29.9 \mathrm{Mb}$. Thus it could be a candidate for stunting resistance QTL stre1 near marker nga111 at $27.3 \mathrm{Mb}$, but stunting resistance was not observed for Ler in the respective study [26]. The results of the present study suggest that the symptoms stunting and systemic spread are controlled by different pathways. This underlines the observation that shoot colonisation is not a prerequisite to cause damage to the host in greenhouse or growth chamber assays, which has also been described before for Brassica [2,51]. As stunting can occur without detectable amounts of $V$. longisporum in the shoot, a translocated signal is likely to be involved in the induction of stunting. Verticillium has been shown to interfere with various signalling pathways, like ABA, ethylene, jasmonic acid and salicylic acid [26,27,29,67]. Some components are obviously important for conferring resistance, since mutants in the ethylene or ABA signalling components ein2, ein4, ein 6 and aba2 are more susceptible to Verticillium than wild type in terms of chlorosis and/or stunting. However, some regulatory mechanisms, especially ethylene production, also seem to be manipulated in a way that enhances disease symptoms in the host plant $[27,68]$. Plants deficient for the ethylene receptor etr 1 showed enhanced resistance in terms of chlorosis [27,29] and fresh weight loss [26] compared to wild type. Our understanding of the nature and exact role of fungal and plant signals in the context of this pathosystem is only at the beginning [69]. A fungal elicitor protein, Verticillium dahliae-necrosis-andethylene-inducing factor (VdNEP), was found to be involved in symptom development in cotton [70] and is also present in V. longisporum (Weiberg and Karlovsky, unpublished results), emphasizing the role of ethylene induction in Verticillium pathogenesis.

The alteration of the $A$. thaliana branching pattern after Verticillium infection has previously been observed for the A. thaliana ecotypes C24 and 'Coimbra' (Co-1) [29]. 
Scoring the (Bur $\times$ Ler) F3-families for basal branch numbers gave clear results for all three experiments. Both loci were on chromosome 1 and together accounted for $72 \%$ of the total variation in experiment E1. vab1 had a stronger effect and was located shortly below marker F16J7TRB (3.8 Mb, AGI physical map). A promising candidate for vab1 could be supershoot (sps) at $5.6 \mathrm{Mb}$. It encodes a P450 cytochrome oxidase (EC 1.9.3.1) that regulates axillary branching by locally modulating cytokinin levels in the leaf axils [71]. Allelic variation of sps is significantly associated with basal branching patterns among natural $A$. thaliana populations [72]. A possible explanation for the differences in the present study would be that Verticillium interferes with cytokinin or other hormonal regulatory pathways, but not every natural sps allele responds to phytohormones in the same way. Other possible candidates for vab1 include bud1 at $6.3 \mathrm{Mb}$, encoding a MAP kinase kinase (EC 2.7.12.2) involved in auxin transport and systemic acquired resistance [73], and $m p$, an auxin-response factor at 6.9 Mb [74]. vab2, the weaker branching QTL, was located between markers nga392 at $9.8 \mathrm{Mb}$ and EH12 at $12.8 \mathrm{Mb}$. A gene in this region influencing branching pattern is axr3 at $11.6 \mathrm{Mb}$ involved in auxin signalling [75]. Whereas ethylene and ABA-signalling have been in the focus of Verticillium researchers [26,27,29], there is no evidence so far for a possible role of cytokinin and auxin. The findings of the present study show that the roles of cytokinin and auxin signalling in Verticillium pathogenesis require further investigation.

The search for genetic resources mediating Verticillium resistance in Brassica has been difficult because qualitative resistance relying on a single gene is not available for this pathosystem. In breeding, quantitative resistance is more difficult to implement as it is mostly controlled by several genes with small effects, and it demands more effort to introgress quantitative resistance. Nevertheless, it is of high interest to breeders since it is often more durable than qualitative resistance. For some pathogens it is the only resistance available $[12,18,19]$. In greenhouse experiments, A. thaliana has proven to be a good model for genetic studies on quantitative resistance against $V$. longisporum in crucifers. The complexity of Verticillium resistance in A. thaliana was particularly striking for stunting resistance, which was highly conditional on environmental factors in the present study. A combination of several QTL was necessary to confer good growth performance regardless of different developmental patterns and growing conditions. Fungal spread within the plant was not a prerequisite for increased symptom severity in $A$. thaliana, but is likely to play a greater role for Brassica crops in the field, as host colonisation enables the fungus to use more host resources for its own proliferation. In Brassica, disease symptoms were indeed correlated with the presence of $V$. longisporum in shoots [[5,24], S. Konietzki, FU Berlin, personal communication]. Breeding for resistance to systemic spread should be a promising strategy to control this disease in Brassica. The present genetic study in A. thaliana provides the basis for the identification of individual resistance genes, their cloning, and the elucidation of the resistance mechanisms involved.

\section{Conclusions}

A. thaliana can be used as a model to study typical features of the $V$. longisporum pathosystem, such as host genotype and developmental effects on pathogenesis and resistance components. Systemic spread of $V$. longisporum in the host as well as resistance to this major disease trait are described for the first time in natural $A$. thaliana accessions. This creates the possibility to study a major resistance mechanism against vascular pathogens in this model plant and to clone relevant genes of the involved pathways using the Arabidopsis tool box. Stunting resistance and resistance to systemic spread were controlled by different QTL and should be treated as separate traits. Developmental and environmental effects on pathogenesis and resistance need to be considered when designing and interpreting experiments in research and breeding. Further studies will help to determine the exact role of potential candidate genes.

\section{Additional material}

Additional file 1: New sequence-characterised (SCAR) markers developed for (BurXLer) mapping populations. New markers are listed with name, chromosomal position according to the AGI map, sequences of forward and reverse primers, the annealing temperature for PCRamplification and the fragment size for Bur and Ler respectively. Length polymorphisms were identified using the MSQT query tool [36].

Additional file 2: Linkage map for the (BurXLer) F2 mapping population. The linkage map shows the five $A$. thaliana chromosomes containing all markers that were analysed. Physical positions of markers according to the $\mathrm{AGI}$ map and marker distances in $\mathrm{CM}$ as determined in the F2 population are displayed.

Additional file 3: Frequency distributions for trait values of F3families in individual infestation experiments. Frequency distributions of F3-family values are shown for all three infestation experiments for the following traits: degree of Verticillium colonisation, development time, stunting resistance and Verticillium-induced axillary branching. Parental and F1-values are indicated by boxes.

Additional file 4: QTL information for individual infestation experiments. Peak positions, LRS values and significance levels of QTL in the individual infestation experiments are listed for the following traits: degree of Verticillium colonisation, development time, stunting resistance and Verticillium-induced axillary branching.

Additional file 5: Tests of between-subjects effects in two-factor ANOVA. Two-factor ANOVA was performed to test the influence of genotype and experiment and their interaction on trait values. Results of tests of between-subjects effects are shown for the traits development time, fresh weight of inoculated plants, and the height of inoculated plants (height of plants with and without erecta phenotype were tested separately). 


\section{Acknowledgements}

We gratefully acknowledge financial support from the Deutsche Forschungsgemeinschaft (DFG), Bonn, Germany (FOR546/Di-1502/1-1 grant), the Berliner Programm zur Förderung der Chancengleichheit von Frauen in Forschung und Lehre and the Norddeutsche Pflanzenzucht (NPZ), Germany. We are grateful to Thomas Schmülling for hosting and supporting this project and we thank Maike Nibbrig, Heike Rollwage, Sandra Seeher and Claudia Terasa for excellent technical support. Karen Zeise, Berlin, Germany, is gratefully acknowledged for supplying the fungal strain. We also thank Susanne King-Jones and Anahid Powell, who carefully edited the manuscript.

\section{Author details}

${ }^{1}$ Freie Universität Berlin, Institut für Biologie - Angewandte Genetik, AlbrechtThaer-Weg 6, 14195 Berlin, Germany. ${ }^{2}$ Georg-August-Universität Göttingen, Department of Crop Science, Molecular Phytopathology and Mycotoxin Research Unit, Grisebachstraße 6, 37077 Göttingen, Germany.

\section{Authors' contributions}

EH planned and carried out all plant experiments, all experiments related to mapping such as marker analysis, mapping and QTL analysis and drafted the manuscript. ED conceived of the study, participated in its design and coordination and helped to draft the manuscript. PK provided the GPCR data on fungal biomass and helped to draft the manuscript. All authors read and approved the final manuscript.

Received: 29 June 2010 Accepted: 2 November 2010 Published: 2 November 2010

\section{References}

1. Tjamos EC, Beckmann C: Vascular wilt diseases of plants: Basic studies and control. Berlin: Springer; 1989.

2. Eynck C, Koopmann B, Grunewaldt-Stoecker G, Karlovsky P, von Tiedemann A: Differential interactions of Verticillium longisporum and $V$. dahliae with Brassica napus detected with molecular and histological techniques. Eur J Plant Pathol 2007, 118:259-274.

3. Zhou L, Hu Q, Johansson A, Dixelius C: Verticillium longisporum and V. dahliae: infection and disease in Brassica napus. Plant Pathol 2006, 55:137-144.

4. Debode J, Declercq B, Höfte M: Identification of cauliflower cultivars that differ in susceptibility to Verticillium longisporum using different inoculation methods. J Phytopathol 2005, 153:257-263.

5. Eynck C, Koopmann B, Karlovsky P, von Tiedemann A: Internal resistance in winter oilseed rape inhibits systemic spread of the vascular pathogen Verticillium longisporum. Phytopathology 2009, 99:802-811.

6. Harrison NA, Beckman CH: Time/space relationships of colonization and host response in wilt-resistant and wilt-susceptible cotton (Gossypium) cultivars inoculated with Verticillium dahliae and Fusarium oxysporum f. sp. vasinfectum. Physiol Plant Pathol 1982, 21:193-207.

7. Markakis EA, Tjamos SE, Antoniou PP, Paplomatas EJ, Tjamos EC: Symptom development, pathogen isolation and real-time QPCR quantification as factors for evaluating the resistance of olive cultivars to Verticillium pathotypes. Eur J Plant Pathol 2009, 124:603-611.

8. Mercado-Blanco J, Collado-Romero M, Parrilla-Araujo S, Rodríguez-Jurado D, Jiménez-Díaz RM: Quantitative monitoring of colonization of olive genotypes by Verticillium dahliae pathotypes with real-time polymerase chain reaction. Physiol Mol Plant Pathol 2003, 63:91-105.

9. Shaw DV, Gordon TR, Hansen J, Kirkpatrick SC: Relationship between the extent of colonization by Verticillium dahliae and symptom expression in strawberry (Fragaria $\times$ ananassa) genotypes resistant to verticillium wilt. Plant Pathol 2010, 59:376-381.

10. Parlevliet JE: Components of resistance that reduce the rate of epidemic development. Ann Rev Phytopathol 1979, 17:203-222.

11. Tooley PW, Grau CR: The relatioship between rate-reducing resistance to Phytophthora megasperma f. sp. glycinea and yield of soybean. Phytopathology 1984, 74:1209-1216.

12. Njiti VN, Suttner RJ, Gray LE, Gibson PT, Lightfoot DA: Rate-reducing resistance to Fusarium solani. f. sp. phaseoli underlies field resistance to soybean sudden death syndrome. Crop Sci 1997, 37:132-138.
13. Tooley PW, Grau CR: Field characterization of rate-reducing resistance to Phytophthora megasperma f. sp. glycinea in Soybean. Phytopathology 1984, 74:1201-1208.

14. Karapapa VK, Bainbridge BW, Heale JB: Morphological and molecular characterization of Verticillium longisporum comb. nov., pathogenic to oilseed rape. Mycol Res 1997, 101:1281-1294.

15. Dixelius C, Happstadius I, Berg G: Verticillium wilt on Brassica oil crops - a Swedish perspective. J Swed Seed Assoc 2005, 115:36-48.

16. Krüger W: Untersuchungen zur Verbreitung von Verticillium dahliae Kleb. und anderen Krankheits- und Schaderregern bei Raps in der Bundesrepublik Deutschland. Nachrichtenbl Deutsch Pflanzenschutzd 1989, 41:49-56.

17. Rygulla W, Snowdon RJ, Eynck C, Koopmann B, von Tiedemann A, Lühs W, Friedt W: Broadening the genetic basis of Verticillium longisporum resistance in Brassica napus by interspecific hybridisation. Phytopathology 2007, 97:1391-1396.

18. Poland JA, Balint-Kurti PJ, Wisser RJ, Pratt RC, Nelson RJ: Shades of gray: the world of quantitative disease resistance. Trends Plant Sci 2008, 14:21-29.

19. Njiti VN, Lightfoot DA: Genetic analysis infers DT loci underlie resistance to Fusarium solani f. sp. glycines in indeterminate soybeans. Can J Plant Sci 2006, 86:83-90.

20. Happstadius I, Ljungberg A, Kristiansson B, Dixelius C: Identification of Brassica oleracea germplasm with improved resistance to Verticillium wilt. Plant Breed 2003, 122:30-34.

21. Zeise K: Screening for resistance to Verticillium dahliae Kleb. on oilseed rape (Brassica napus L. var. oleifera Metzger) under greenhouse conditions. Nachrichtenbl Deutsch Pflanzenschutzd 1992, 44:125-128.

22. Rygulla W, Snowdon RJ, Friedt W, Happstadius I, Cheung WY, Chen D: Identification of quantitative trait loci for resistance against Verticillium longisporum in oilseed rape (Brassica napus). Phytopathology 2008, 98:215-221.

23. Hornig H: Krankhafte Abreife - Spätschäden durch Phoma lingam und/ oder Verticillium dahliae. Raps 1986, 4:83-85.

24. Dunker S, Keunecke H, Steinbach P, von Tiedemann A: Impact of Verticillium longisporum on yield and morphology of winter oilseed rape (Brassica napus) in relation to systemic spread in the plant. J Phytopathol 2008, 156:698-707.

25. Ellendorff $\mathrm{U}$, Fradin EF, Jonge Rd, Thomma BPHJ: RNA silencing is required for Arabidopsis defense against Verticillium wilt disease. J Exp Bot 2009, 60:591-602.

26. Johansson A, Staal J, Dixelius C: Early responses in the ArabidopsisVerticillium longisporum pathosystem are dependent on NDR1, JA- and ET-associated signals via cytosolic NPR1 and RFO1. Mol Plant Microbe Interact 2006, 19:958-969.

27. Pantelides IS, Tjamos SE, Paplomatas EJ: Ethylene perception via ETR1 is required in Arabidopsis infection by Verticillium dahliae. Mol Plant Pathol 2010, 11:191-202.

28. Steventon $L A$, Okori $P$, Dixelius $C$ : An investigation of the susceptibility of Arabidopsis thaliana to isolates of two species of Verticillium. $J$ Phytopathol 2001, 149:395-401.

29. Veronese P, Narasimhan ML, Stevenson RA, Zhu JK, Weller SC, Subbarao KV, Bressan RA: Identification of a locus controlling Verticillium disease symptom response in Arabidopsis thaliana. Plant J 2003, 35:574-587.

30. Kranz AR, Kirchheim B: Genetic resources in Arabidopsis. Arabidopsis Information Service Newsletter 1985, 24:1-368.

31. Zeise $K$, von Tiedemann A: Host specialization among vegetative compatibility groups of Verticillium dahliae in relation to Verticillium longisporum. J Phytopathol 2002, 150:112-119.

32. Brandfass C, Karlovsky P: Simultaneous detection of Fusarium culmorum and $F$. graminearum in plant material by duplex PCR with melting curve analysis. BMC Microbiol 2006, 6:4.

33. The Arabidopsis information resource (TAIR). [http://www.arabidopsis.org].

34. O'Neill CM, Morgan C, Kirby J, Tschoep H, Deng PX, Brennan M, Rosas U, Fraser F, Hall C, Gill S, et al: Six new recombinant inbred populations for the study of quantitative traits in Arabidopsis thaliana. Theor Appl Genet 2008, 116:623-634.

35. Nordborg M, Hu TT, Ishino Y, Jhaveri J, Toomajian C, Zheng H, Bakker E, Calabrese P, Gladstone J, Goyal R, et al: The pattern of polymorphism in Arabidopsis thaliana. PLoS Biol 2005, 3:1289-1299. 
36. Warthmann N, Fitz J, Weigel D: MSQT for choosing SNP assays from multiple DNA alignments. Bioinformatics 2007, 23(20):2784-7.

37. Torii KU, Mitsukawa N, Oosumi T, Matsuura Y, Yokoyama R, Whittier RF, Komeda Y: The Arabidopsis ERECTA gene encodes a putative receptor protein kinase with extracellular leucine-rich repeats. Plant Cell 1996, 8:735-746.

38. Rogers SO, Bendich AJ: Extraction of DNA from milligram amounts of fresh, herbarium and mummified plant tissues. Plant Mol Biol 1985, 5:69-76.

39. Lorieux M: 2008 [http://mapdisto.free.fr/]

40. Manly KF, Cudmore RH, Meer JM: Map Manager QTX, cross-platform software for genetic mapping. Mamm Genome 2001, 12:930-932.

41. Collard BCY, Jahufer MZZ, Brouwer JB, Pang ECK: An introduction to markers, quantitative trait loci (QTL) mapping and marker-assisted selection for crop improvement: The basic concepts. Euphytica 2005, 142:169-196.

42. Falconer DS, Mackay TFC: Introduction to quantitative genetics. Harlow: Longmans Green; 41996.

43. Cahaner A, Hillel J: Estimating heritability and genetic correlation between traits from generations F2 and F3 of self-fertilizing species: A comparison of three methods. Theor Appl Genet 1980, 58:33-38.

44. Häffner E, Konietzki S, Socquet-Juglard D, Gerowitt B, Diederichsen E: Genetics of resistance against the vascular pathogen Verticillium longisporum in Brassica and Arabidopsis thaliana. In Crop plant resistance to biotic and abiotic factors: Current potential and future demands 3rd international symposium on plant protection and plant health in Europe. Edited by: Feldmann F, Alford DV, Furk C. Berlin: Deutsche Phytomedizinische Gesellschaft; 2009:385-392.

45. Brandfass $C$, Karlovsky P: Upscaled CTAB-based DNA extraction and realtime PCR assays for Fusarium culmorum and F. graminearum DNA in plant material with reduced sampling error. Int J Mol Sci 2008, 9:2306-2321.

46. Godiard L, Sauviac L, Torii KU, Grenon O, Mangin B, Grimsley NH, Marco Y: ERECTA, an LRR receptor-like kinase protein controlling development pleiotropically affects resistance to bacterial wilt. Plant J 2003, 36:353-365.

47. Llorente F, Alonso-Blanco C, Sánchez-Rodriguez C, Jorda L, Molina A: ERECTA receptor-like kinase and heteromeric $\mathrm{G}$ protein from Arabidopsis are required for resistance to the necrotrophic fungus Plectosphaerella cucumerina. Plant J 2005, 43:165-180.

48. Benhamou N: Ultrastructural and cytochemical aspects of the response of eggplant parenchyma cells in direct contact with Verticillium-infected xylem vessels. Physiol Mol Plant Pathol 1995, 46:321-338.

49. Daayf F, Nicole M, Boher B, Pando A, Geiger JP: Early vascular defense reactions of cotton roots infected with a defoliating mutant strain of Verticillium dahliae. Eur J Plant Pathol 1997, 103:125-136.

50. Tappe $\mathrm{H}$ : Verticillium longisporum induced gene expression in Arabidopsis thaliana. Dissertation Göttingen: Georg-August-Universität zu Göttingen; 2008.

51. Floerl S, Druebert C, Majcherczyk A, Karlovsky P, Kues U, Polle A: Defense reactions in the apoplastic proteome of oilseed rape (Brassica napus var. napus) attenuate Verticillium longisporum growth but not disease symptoms. BMC Plant Biol 2008, 8:129.

52. Doxey AC, Yaish MWF, Moffatt BA, Griffith M, McConkey BJ: Functional divergence in the Arabidopsis $\beta-1.3$ glucanase gene family inferred by phylogenetic reconstruction of expression states. Mol Biol Evol 2007, 24:1045-1055.

53. Schroeder HW, Christensen JJ: Factors affecting the resistance of wheat scab caused by Gibberella zeae. Phytopathol 1963, 53:831-838.

54. Buerstmayr H, Steiner B, Hartl L, Griesser M, Angerer N, Lengauer D, Miedaner T, Schneider B, Lemmens M: Molecular mapping of QTLs for Fusarium head blight resistance in spring wheat. II. Resistance to fungal penetration and spread. Theor Appl Genet 2003, 107:503-508.

55. Chung CL, Longfellow JM, Walsh EK, Kerdieh Z, Esbroeck GV, Balint-Kurti PJ, Nelson RJ: Resistance loci affecting distinct stages of fungal pathogenesis: use of introgression lines for QTL mapping and characterisation in the maize - Setosphaeria turcica pathosystem. BMC Plant Biol 2010, 10:103.

56. Johanson U, West J, Lister C, Michaels S, Amasino R, Dean C: Molecular analysis of FRIGIDA, a major determinant of natural variation in Arabidopsis flowering time. Science 2000, 290:344-347.
57. Ahmad M, Cashmore AR: HY4 gene of $A$. thaliana encodes a protein with characteristics of a blue-light photoreceptor. Nature 1993, 366:162-166

58. Pepper A, Delaney T, Washburn T, Poole D, Chory J: DET1, a negative regulator of light-mediated development and gene expression in Arabidopsis, encodes a novel nuclear-localised protein. Cell 1994, 78:109-116.

59. Pepper AE, Chory J: Extragenic suppressors of the Arabidopsis det1 mutant identify elements of flowering-time and light-response regulatory pathways. Genetics 1997, 145:1125-1137.

60. Koornneef $\mathrm{M}$, Hanhart $\mathrm{CJ}$, Veen JHVd: A genetic and physiological analysis of late flowering mutants in Arabidopsis thaliana. Mol Gen Genet 1991, 229:57-66

61. Macknight R, Bancroft I, Page T, Lister C, Schmidt R, Love K, Westphal L, Murphy G, Sherson S, Cobbett $C$, et al: $F C A$, a gene controlling flowering time in Arabidopsis, encodes a protein containing RNA-binding domains. Cell 1997, 89:737-745.

62. Michaels SD, Amasino RM: Loss of FLOWERING LOCUS C activity eliminates the late-flowering phenotype of FRIGIDA and autonomous pathway mutations, but not responsiveness to vernalisation. Plant Cell 2001, 13:935-941.

63. Werner JD, Borevitz JO, Uhlenhaut NH, Ecker JR, Chory J, Weigel D: FRIGIDA-independent variation in flowering time of natural Arabidopsis thaliana accessions. Genetics 2005, 170:1197-1207.

64. Sheldon CC, Rouse DT, Finnegan EJ, Peacock WJ, Dennis ES: The molecular basis of vernalization: The central role of FLOWERING LOCUS C (FLC). Proc Nat Acad Sci USA 2000, 97:3753-3758.

65. Develey-Rivière MP, Galiana E: Resistance to pathogens and host developmental stage: a multifaceted relationship within the plant kingdom. New Phytol 2007, 175:405-416.

66. Whalen MC: Host defense in a developmental context. Mol Plant Pathol 2005, 6:347-360.

67. Ratzinger A, Riediger N, von Tiedemann A, Karlovsky P: Salicylic acid and salicylic acid glucoside in xylem sap of Brassica napus infected with Verticillium longisporum. J Plant Res 2009, 122:571-579.

68. Robison MM, Shah S, Tamot B, Pauls KP, Moffatt BA, Glick BR: Reduced symptoms of Verticillium wilt in transgenic tomato expressing a bacterial ACC deaminase. Mol Plant Pathol 2001, 2:135-145.

69. Fradin EF, Thomma BPHJ: Physiology and molecular aspects of Verticillium wilt diseases caused by $V$. dahliae and V. albo-atrum. Mol Plant Pathol 2006, 7:71-86.

70. Wang JY, Cai Y, Gou JY, Mao YB, Xu YH, Jiang WH, Chen XY: VdNEP, an elicitor from Verticillium dahliae, induces cotton plant wilting. App/ Environ Microbiol 2004, 70:4989-4995.

71. Tantikanjana T, Yong JWH, Letham DS, Griffith M, Hussain M, Ljung K, Sandberg G, Sundaresan V: Control of axillary bud initiation and shoot architecture in Arabdiopsis through the SUPERSHOOT gene. Genes Dev 2001, 15:1577-1588.

72. Ehrenreich IM, Stafford PA, Purugganan MD: The genetic architecture of shoot branching in Arabidopsis thaliana: A comparative assessment of candidate gene associations vs. quantitative trait locus mapping. Genetics 2007, 176:1223-1236.

73. Zhang X, Dai Y, Xiong Y, DeFraia C, Li J, Dong X, Mou Z: Overexpression of MAP kinase kinase 7 leads to activation of plant basal and systemic acquired resistance. Plant J 2007, 52:1066-1079.

74. Hardtke CS, Berleth T: The Arabidopsis gene MONOPTEROS encodes a transcription factor mediating embryo axis formation and vascular development. EMBO J 1998, 17:1405-1411.

75. Cline MG, Chatfield SP, Leyser O: NAA restores apical dominance in the axr3-1 mutant of Arabidopsis thaliana. Ann Bot 2001, 87:61-65.

\section{doi:10.1186/1471-2229-10-235}

Cite this article as: Häffner et al:: Genetic and environmental control of the Verticillium syndrome in Arabidopsis thaliana. BMC Plant Biology 2010 10:235. 